\title{
EL PERIODISMO EN EL ESPEJO. LA PROFESIÓN ANALIZADA POR PERIODISTAS ANDALUCES1
}

\author{
Juan Carlos Suárez Villegas \\ (Universidad de Sevilla) \\ jcsuarez@us.es \\ Lorena R. Romero Domínguez \\ (Universidad de Sevilla) \\ lorenaromero@us.es \\ Ana Almansa Martínez \\ (Universidad de Málaga) \\ anaalmansa@uma.es
}

\begin{abstract}
Resumen: La organización profesional, la precariedad laboral, las presiones de los propios medios, la ética de los profesionales a la hora de elaborar la información o su sensibilidad frente a los problemas sociales, fueron los ejes de la entrevista en profundidad realizada a veinticuatro periodistas andaluces para reflexionar en voz alta sobre su propia profesión en nuestra sociedad. En este artículo explicamos los motivos de nuestra investigación y las cuestiones más relevantes que se pusieron de manifiesto en sus discursos.
\end{abstract}

Palabras clave: Ética, periodismo, principio de justicia, principio de independencia, principio de diligencia, principio de responsabilidad.

Abstract: Professional arrangement, job insecurity, media pressure, journalists' ethic facing and developing news, their sensitivity to inform, the way to understand social problems, those questions were starting points to elaborate an interview carried out with 24 Andalucian journalists. This article shows the reasons which lead us through the investigation and many important questions pointed out by interviewed people.

Keywords: Ethic, journalism, justice principia, independence principia, diligence principia, responsibility principia.

\footnotetext{
${ }^{1}$ Este articulo se ha realizado dentro del marco del Proyecto de I+D+l del MEC, convocatoria del 2006, titulado "Ética y excelencia informativa. La deontología periodística frente a las expectativas de los ciudadanos" ( $n^{\circ}$ de referencia: SEJ2006-05631-C). En dicho proyecto participaron cuatro Universidades Españolas: La Universidad Carlos III, La Universidad de El País Vasco, La Universidad Pompeu Fabra y la Universidad de Sevilla.
} 
El periodismo en el espejo.

La profesión analizada por periodistas andaluces

\section{INTRODUCCIÓN}

as asociaciones profesionales (Federación Andaluza de Asociaciones de la Prensa y Sindicato de Periodistas de Andalucía) y periodistas en general vienen denunciando la situación del periodismo en Andalucía, descubriendo las situaciones en las que entienden se conculcan los derechos laborales de los periodistas. La precariedad laboral en el sector está teniendo consecuencias en la profesión y, aunque existen desde hace años Códigos Deontológicos, en una situación laboral precaria es muy difícil preocuparse por cumplir lo que estos marcan. Así lo constatan testimonios de periodistas andaluces, que relacionan directamente el crecimiento de la precariedad laboral con el auge del sensacionalismo y de comportamientos que no se ajustan a la deontología profesional.

Hoy día el periodismo se ejerce en el seno de la empresa informativa. La Constitución garantiza el derecho a la información y la libertad de expresión de todos los ciudadanos. Pero, además de un derecho subjetivo, el derecho a la información constituye también una institución de la sociedad democrática, el cual puede ser ejercitado en gran medida gracias a la labor que desempeñan los medios de comunicación. El derecho a la información en su vertiente pasiva, es decir, el derecho a ser informado, difícilmente se podría lograr sin el concurso de unos importantes agentes que cumplen la función institucional de actuar de correa de transmisión entre los poderes políticos y la ciudadanía. Por otro lado, la independencia de los medios de comunicación constituye un basamento fundamental para garantizar una opinión pública plural dentro de la propia sociedad civil, concitando acuerdos que puedan actuar como voces críticas y vigilantes del poder político.

Pero esta libertad de la que gozan los medios de comunicación en la sociedad democrática no siempre se traslada al seno de las redacciones. No en vano, el profesor Manuel Núñez Encabo ha reiterado que el gran reto de los denominados países democráticos no radica tanto en exigir la libertad de expresión de los medios de comunicación, sino en los medios de comunicación, pues estos actúan con frecuencia como comparsa de poderes políticos y económicos, exigiendo criterios de autocensuras informativas como condición para conservar el puesto de trabajo. Por eso, se precisa debatir sobre la ética de los medios de comunicación como un acuerdo que involucre a todos los agentes que participan en el proceso informativo. En una sociedad globalizada, en la que la imagen es especialmente el mensaje, se precisa más una ética de los medios de comunicación, en sus distintos formatos, que una ética de la profesión como colectivo frente al resto de agentes implicados.

Por esta razón, quisimos contar para esta investigación con periodistas implicados en distintos niveles de responsabilidad dentro de la profesión, desde directores de medios, jefe de redacción, simples redactores o becarios. Esta perspectiva plural podría aportarnos algunas de las claves sobre los obstáculos que en los distintos escalones de la pirámide profesional podrían obstaculizar el compromiso de los informadores con la ciudadanía. 
Por una vez, se trataba de la compleja tarea de contar lo que uno hace, que el sujeto se convierta en objeto de la información y sea él mismo quien interprete la información a través de las propias condiciones en las que ésta se produce. Una inversión del espejo, el informador construyendo el relato de su realidad. Una mirada introspectiva que puede ayudar a repensar la información remitiéndonos a su auténtica fuente: el periodista. Y de manera más certera, abordando la profesión como institución social a través de la cual se canaliza la comunicación pública. Esta doble vertiente, institucional y profesional, puede contribuir a ver de qué modo la ética del periodista no se puede entender sin la ética del periodismo $y$, particularmente, sin una ética de los medios de comunicación. Dicha razón inspiró el Proyecto de Excelencia "Ética en la comunicación. La expectativa de la ciudadanía frente a los medios", en el cual participamos cuatro universidades españolas, con el afán de poner de manifiesto las percepciones que unos y otros tienen en la importante tarea de recuperar la dignidad de la información como un bien fundamental para la pervivencia de la sociedad democrática.

La primera fase de dicha investigación se llevó a cabo durante los meses de junio y julio de 2008. Se trataba de saber qué pensaban los periodistas sobre su propia labor y su responsabilidad social. Algunos nos comentaron que la entrevista le había resultado una experiencia casi psicoanalítica, pues le había hecho pensar sobre el sentido de su propio trabajo, sobre las causas por las que el periodismo puede perder la confianza y el afecto de su público. ¿Qué puede fallar? ¿Qué parte de responsabilidad pueden tener en prácticas informativas viciadas y qué se asume sin deparar en sus efectos? ¿Cuánto es parte de la presión impuesta por los medios? ¿Por qué se acepta la precariedad laboral? ¿Qué puede hacer la profesión para defenderse de esta inercia que contamina la actividad informativa desde dentro?

La impresión generalizada que obtuvimos de la mayoría de los casos fue una cierta impotencia, con el consiguiente conformismo de que nada se podía hacer para afrontar males endémicos que están arraigados tanto en la propia manera de entender la información como en la carente estructura organizativa de una profesión en la que los más desaprensivos medran con más rapidez. La ética queda como un compromiso exclusivamente personal y, en cualquier caso, útil si no se plantea como una alternativa incompatible con la estabilidad laboral.

La entrevista se realizó a periodistas andaluces de distinta edad, sexo, medio de comunicación, responsabilidad dentro del medio y secciones informativas. Se trata de tener una muestra representativa en la que puedan detectarse las diferencias y afinidades en el modo de abordar los problemas los distintos periodistas andaluces. La edad media de los entrevistados fue de 36 años y se mantuvo un criterio paritario entre hombres y mujeres. De cada cinco entrevistados, cuatro eran redactores y uno tenía responsabilidad directiva dentro del medio. La mayoría eran licenciados en periodismo, nueve de cada diez, mientras que dos de cada tres no pertenecen a ninguna asociación de periodistas. El 25\% de los periodistas ejercían su trabajo en gabinetes de comunicación, mientras que el 
$75 \%$ restante trabaja en medios de comunicación, manteniendo una posición muy similar entre televisión, radio, prensa y agencia. También se entrevistaron freelance o periodistas con experiencia en el ámbito de los periódicos digitales.

La encuesta estaba planteada en cuatro bloques, con los que pretendíamos cumplir los cuatros pilares básicos de la ética periodística:

1. El principio de justicia. De qué modo se puede organizar la profesión para garantizar que los derechos y deberes de los periodistas sean iguales para todos.

2. El principio de independencia. De qué modo el periodista puede reivindicar su estatus profesional y su compromiso con la ciudadanía por encima de presiones del propio medio.

3. El principio de diligencia. Qué se entiende por veracidad. De qué modo se asegura a través del proceso informativo el derecho a la información de los ciudadanos.

4. El principio de responsabilidad. Qué piensan los periodistas sobre los efectos que tienen sobre la ciudadanía su labor informativa.

Con este modelo de entrevista queríamos saber qué piensan los periodistas sobre estos cuatro aspectos: ¿cómo debe organizarse la profesión?, ¿cómo se puede ser independiente?, ¿cómo se puede informar de manera diligente?, ¿cómo se valora la actuación de los medios de comunicación frente a los ciudadanos?

En el apéndice al final de este artículo incluimos el modelo de entrevista que utilizamos para nuestra investigación. El primer bloque de cuestiones, englobadas bajo el epígrafe "Organización profesional y mecanismos de regulación", pretendía conocer qué modelo consideran los profesionales más adecuados para defender sus derechos y también de qué modo podrían establecerse mecanismos de regulación que contaran con la confianza de los propios profesionales. Las preguntas iban dirigidas a averiguar si preferían como modelo de organización los sindicatos, el colegio profesional o las asociaciones de prensa y, en el caso de mecanismos de control, su criterio sobre la denominada autorregulación, ejercida desde instancias profesionales, la corregulación, con la participación de agentes institucionales, o directamente medidas de heterocontrol, procedentes de la acción de instituciones independientes que velen por los contenidos y responsabilidades de los medios de comunicación.

En el segundo bloque, titulado "La independencia del profesional frente a las presiones externas e internas", se aludía a cuestiones relativas a la propia percepción que los periodistas tienen sobre su libertad a la hora de informar. Cuestiones como las de qué actitud adoptar ante regalos de terceros por la labor periodística o la compatibilidad entre periodismo y otras actividades, eran algunas de las preguntas que buscaban deslindar la información de otros intereses adheridos que pueden terminar incluso por suplantarla. 
En el tercer bloque incluimos todas las cuestiones relativas a lo que podríamos denominar el paradigma de diligencia profesional, "La diligencia en el proceso informativo". Qué tratamiento dar a la fuente, si se debe utilizar o no cámaras ocultas para conseguir cierta información, cómo garantizar la verdad informativa o cuál debe ser la posición del periodista en relación a posibles rectificaciones de sus noticias, etc., fueron algunos de los aspectos planteados a los entrevistados.

Por último, el cuarto bloque recogía las denominadas cuestiones acerca de "La responsabilidad de los medios de comunicación frente a la ciudadanía". ¿Están los medios pensando en los efectos de sus opciones informativas? ¿Se plantea el periodista si su actividad repercute de algún modo en la ciudadanía? En este bloque se pregunta por el tratamiento de los menores en la programación, el honor de las personas afectadas por la información o asuntos relativos a las posibles consideraciones sobre la denomina prensa rosa.

\section{LOS RESULTADOS DE LAS ENTREVISTAS EN PROFUNDIDAD}

\subsection{Organización profesional y mecanismos de autorregulación}

Más de la mitad de los entrevistados $(66,8 \%)$ cree que los medios de comunicación deben ser controlados por una instancia independiente que vele por el pluralismo informativo y por la protección de los derechos de los ciudadanos. Según las opiniones manifestadas, una instancia reguladora independiente es fundamental para respetar la ética y las buenas prácticas periodísticas en aspectos relativos a la veracidad, la pluralidad y la calidad de los contenidos. Para los periodistas, dicho organismo, según los datos extraídos, debe velar por la calidad de la información y no por el control, ya que esto último suscita ciertas reminiscencias negativas entre los profesionales, al poder equipararse a una estrategia censora. Se ratifica, en todo caso, entre los encuestados que tiene que haber "control y no controladores" y, en cuanto a su composición, debería estar formado por profesionales de la comunicación, sin injerencias de figuras políticas u otro tipo de agentes sociales. En el apartado referido a los Consejos Audiovisuales los encuestados opinan que tiene que concebirse y actuar como "un observatorio crítico de los medios, no de control".

Prácticamente la totalidad de los entrevistados sostiene que la autorregulación es fundamental, pero ello no significa que los profesionales consideren que es posible su implantación en la sociedad, citando los casos de la publicidad y los códigos de autorregulación en las televisiones en horario infantil. Un incumplimiento que, en su opinión, emana tanto desde el sector de las empresas como de los propios profesionales. Sobre este aspecto la reflexión se plantea sobre si debería darse una corregulación, dado que muchas empresas disponen de un marco para la regulación, aunque no lo cumplan. Para los encuestados el problema se plantea en los obstáculos que tiene el periodista para autorregularse como consecuencia de la precariedad laboral existente y apuntan como solución 
El periodismo en el espejo.

La profesión analizada por periodistas andaluces

"el modelo de quejas norteamericano", donde los problemas de carácter ético se resuelven en la propia redacción. Se habla, en definitiva de una autorregulación con límites, emanada del compromiso de todos los periodistas, sin necesidad de disponer de códigos éticos morales. Para los encuestados que no comparten esta opinión, la necesidad de autorregularse no es tal, ya que basta con fijar los límites de un derecho (el de la información), en otro derecho (el de la intimidad, por ejemplo).

Cuando se les pregunta por las asociaciones, los encuestados reconocen su importancia (indistintamente de su forma: sindical, asociaciones de prensa, colegios), aunque matizan que entre la profesión el grado de asociacionismo es bastante bajo y los periodistas "van por libre". Con respecto a la fórmula de las Asociaciones de Prensa en la Comunidad Autónoma andaluza hay quienes les demandan un mayor activismo a la hora de velar por el ejercicio del periodismo evitando las malas prácticas y las presiones políticas y sociales sobre la profesión. Considerada como una fórmula de asociacionismo obsoleta (tan sólo el 4,3\% considera este tipo de organización como el más conveniente), el resto de los encuestados apuesta por una fórmula mixta, con organizaciones profesionales y sindicatos interrelacionados; las primeras velarían por el buen ejercicio profesional; los segundos, por la precariedad laboral. Más de la mitad de los encuestados $(56,6 \%)$ apoya la creación de un colegio profesional, "la asignatura pendiente del periodismo" en la comunidad, ya que gracias a él se evitaría el intrusismo, se dignificaría el trabajo, y se integraría a todos los profesionales, unas tareas que no pueden aunar ni sindicatos ni las organizaciones existentes en la actualidad.

La mención en el párrafo anterior del intrusismo, nos lleva a abordar este problema entre los encuestados. Aunque la mayoría piensa que "no hay forma de acabar con el intrusismo [puesto que] es la lacra actual", a la hora de mencionar medidas concretas muchos recurren al colegio profesional, al objeto de que desde esta instancia se incapacite para ejercer la profesión a quienes no lo son (restringiendo, por ejemplo, el acceso a los no licenciados a las redacciones de los medios). No obstante, se observa como un problema de carácter empresarial, más que del periodista, porque los empresarios tienen libertad para contratar a no licenciados. Y las repercusiones de estas políticas de contratación afectan directamente a la ciudadanía ya que genera entre las audiencias cierta confusión al no saber quiénes son periodistas.

Para el 91,6\% de los encuestados el periodista debe tener una cualificación específica para poder ejercer la profesión, ya que la información es algo tan transcendente como para que la ejerza quien no esté formado. Curiosamente son algunos de los licenciados en Periodismo $(8,4 \%)$ los que creen que no es necesaria una formación específica, mientras que licenciados en otras materias como Teología o Matemáticas, que ejercen de periodistas, son los que más inciden en la formación específica. A pesar de ello, muchos apuntan que el "título no te hace periodista... te haces periodista en la calle y no al salir de la facultad". Además, 
una vez fuera, se debe hacer una formación continuada, aunque reconocen que ni existen planes de formación ni disponen de tiempo para hacerlos.

Esta ausencia de tiempo nos remite a las condiciones laborales de los periodistas, aspecto en el que muchos consideran que hay graves problemas pues no se cubren las necesidades básicas de contrato, horario y salario. La precariedad laboral afecta a la calidad de la información, como muchos encuestados apuntan, pues "al final se copia y se pega". No sólo la calidad de la información se ve perjudicada por estas circunstancias laborales, sino que también la ética de los periodistas, como apuntan los encuestados, se deteriora. Es opinión generalizada entre los encuestados que un periodista precario es más dócil, y que entre estos profesionales peor pagados muchos pierden su vocación.

Si las condiciones laborales no son las mejores, tampoco se sienten los periodistas muy respaldados a la hora de ejercer sus derechos como profesionales. Entre ellos, el más cuestionado es la cláusula de conciencia, donde un $35 \%$ de los encuestados coinciden en señalar que ni se puede plantear debido a la precariedad laboral que existe, además de por las presiones políticas y económicas. Con respecto al derecho de autor un $25 \%$ apunta que no se reconoce (sobre todo con la irrupción de Internet) y que, cuando existe, no se respeta, aunque es más preocupante la lesión intelectual que la económica. De todos los derechos de los periodistas el que mejor parado sale es el secreto profesional por el respeto hacia la fuente y la pérdida de la misma al vulnerar esta relación de confianza. Para los encuestados, el secreto profesional debe estar por encima de cualquier tipo de presión, siendo necesario preservarlo siempre si el periodista quiere conservar su independencia. La única excepción hecha entre los encuestados a este derecho es la posibilidad de que se ponga en peligro la seguridad de terceras personas o se viole algún derecho fundamental de las mismas. Aunque, en general, se piensa que en ningún caso se puede dejar de preservar ya que "el periodismo para ser útil, necesita de este tipo de privilegios, crear supuestos en los que desaparezcan es propiciar la pérdida del derecho cuando a determinados poderes sociales les interese".

Para la defensa de estos derechos, los periodistas pueden recurrir al Comité Deontológico de la FAPE, un organismo que, no obstante, es desconocido para el $61,9 \%$ de los encuestados. Quienes sí saben de la existencia de este organismo consideran que es una herramienta importante, aunque debe difundir más entre los profesionales sus resoluciones.

\subsection{Independencia del profesional frente a las presiones externas e in- ternas}

Ante determinados regalos y beneficios que puedan ofertarle otras empresas, instituciones o particulares que puedan ser objeto de su actividad periodística, el profesional debe actuar con honestidad y sentido común. Es opinión generalizada entre los encuestados que "no hay nadie que no haya aceptado un detalle de empresas o instituciones", pero al mismo tiempo señalan que aceptar determina- 
El periodismo en el espejo.

La profesión analizada por periodistas andaluces

dos tipos de regalos "es un soborno sutil", y siempre que se entienda como un trato de favor hay que rechazarlo. La solución propuesta es la regulación desde la propia empresa de comunicación y del periodista, ya que "se han dado casos en que no se da una determinada información si la empresa o la institución no paga el viaje al periodista para que cubra dicha información". En este sentido se ve condicionada la independencia, aunque hay también quienes opinan que la ética del periodista no se compra con un regalo y que la asistencia a viajes pagados puede suponer una vía de formación para el profesional, no viéndose condicionada la información.

A la hora de abordar la compatibilidad del periodismo con otras actividades laborales como la publicidad o la política, hay claras diferencias entre quienes piensan que no lo hacen justificando que "todo el periodismo hace propaganda de valores políticos como la democracia o el liberalismo, o comerciales como el consumo". En el extremo opuesto se encuentran quienes afirman que son incompatibles, porque condicionan la información: "no se puede ser notario y protagonista de la noticia", "no se puede dar un informativo y anunciar productos, se pierde credibilidad y objetividad", apuntan algunos, pero en la práctica no se puede exigir que no sea incompatible hacer cuñas que complementan el "ridículo sueldo del periodista". Además, en los medios pequeños hay que hacer cuñas por "supervivencia", en los grandes no se debe porque luego es difícil informar sobre esa empresa.

Sin embargo, todos apuntan que es muy complicado separar la función informativa del medio de comunicación de las presiones que pueda ejercer la empresa para favorecer sus intereses económicos o afinidades políticas. "Hay casos evidentes de censura", porque los medios están mediatizados por las empresas y los partidos políticos. En esta línea, el límite entre una noticia que contenga una información pertinente para los intereses del público y la simple intención de utilizarla como promoción comercial está en el "interés público por encima de todo". El periodista debe juzgar si es de interés general sin valorar si la fuente tiene intereses económicos. Otra forma de verlo es que el límite está en el beneficio del servicio; por ejemplo, en la vacuna contra el cáncer de útero se beneficia una empresa farmacéutica aunque es un bien social.

Aunque, el periodista tiene el derecho y la obligación de saber qué empresa le contrata y aunque la cláusula de conciencia es la que le permitiría que, si la empresa cambia de objetivos o principios, pueda acogerse a ella, la mayoría de los entrevistados afirma que en la práctica esto no se hace y se demanda la mediación de los organismo de regulación para establecer unos mínimos claros.

La inmensa mayoría de profesionales consideran que se está perdiendo "a pasos agigantados" el poder crítico del periodismo para convertirse en un escaparate de los intereses económicos y políticos dominantes en la sociedad. "La pérdida de este carácter crítico del periodismo se debe, entre otras cosas, a la comodidad de recibir las noticias desde los gabinetes de prensa, y al aporte 
económico imprescindible de la publicidad institucional, que resta credibilidad a los mensajes. Los encuestados reconocen que estas informaciones institucionales no se comprueban "por las malas condiciones laborales y económicas", por las rutinas productivas impuestas en las empresas mediáticas, que impiden tener el tiempo suficiente para poder investigar. Además, los encuestados también critican la tendencia implantada en algunas ruedas de prensa de no permitir preguntar al periodista.

Ante el fenómeno de las informaciones institucionales, un $61,9 \%$ de los encuestados reconoce que los gabinetes de prensa, responsables de dichas noticias, sí hacen información, cribando lo que quieren que transcienda a los medios igual que los medios lo hacen con la información que quieren que transcienda a la sociedad. Son facilitadores de información, aunque es el periodista en la redacción quien debe decidir si esa información interesa. La mayoría coincide en reseñar que los gabinetes son un medio de comunicación más con una serie de características peculiares, ya que necesita de otros medios para llegar al público.

\subsection{La diligencia en el proceso informativo}

A la hora de obtener información, los periodistas creen que no se deben utilizar cámaras ocultas porque las fuentes deben saber qué medios se utilizan y el periodista debe estar identificado para ofrecer a la fuente el derecho a decidir si facilita o se niega a dar información. A pesar de reconocer que "es delito", "un atentado contra la libertad de expresión para ganar audiencia", que se ha puesto "de moda y se hace sin escrúpulos", en ocasiones "la cámara es la fuente que informa sin querer hacerlo y hace de fuente no oficial", siendo "la única forma de enseñar la verdad en su estado más puro". El uso de cámaras ocultas, sin embargo, "es más creíble, sobre todo en televisión; aunque el periodista como profesional, debe ser capaz de conseguir información y venderla como creíble sin el uso de ciertos instrumentos". En su uso deben tenerse en cuenta los criterios éticos profesionales; criterios que todavía no están regulados en el panorama que han traído las nuevas tecnologías.

Las informaciones hay que contrastarlas siempre ya que hay "un periodismo interpretativo y de declaraciones y hay que recurrir a las fuentes originales". Sin embargo, la realidad es que se contrastan en función del tipo de información y de la fuente de donde proceda. Si la fuente es de confianza, si es institucional, si tiene mucho peso, o hay "mucha prisa" no se contrastan. No hay que confundir contrastar la noticia con pedir la opinión a los afectados. Contrastar es tener seguridad de que es la verdad. Al hilo de lo anterior, si la fuente es oficial, no es suficiente para dar por válida una noticia: la fuente oficial es una fuente más y hay que actuar como con cualquier otra referencia, siempre que se tenga tiempo y medios, algo de lo que carece la mayoría de los profesionales. Aunque algunos de los encuestados tienen sus dudas al respecto y manifiestan que "si no se pone en duda a las agencias de noticias, no tenemos por qué poner en duda la fuente oficial". 
El periodismo en el espejo.

\section{La profesión analizada por periodistas andaluces}

El off de record hay que respetarlo siempre, si no es así "es una traición a la fuente", excepto cuando atente a los derechos fundamentales, cuando la fuente ha mentido, o la información se utiliza con un fin malévolo o ilícito. El off de record blinda a la fuente, no la información, no el que se dé la noticia. Además hay que respetarlo porque el periodista tiene que "ser respetado y hacerse respetar ante sus fuentes y ante la opinión pública.

En cuanto a si los medios rectifican cuando se equivocan, en general los entrevistados consideran que no lo hacen porque "no somos críticos con nosotros, siempre nos cuesta rectificar" pero reconocen "el daño que se puede hacer al no rectificar dando el mismo tiempo y espacio que se dio a la noticia". El correcto ejercicio del derecho de rectificación se apunta, pues, como una de las asignaturas pendientes de los periodistas. Otro de los problemas mencionados es la difícil separación entre información y opinión, que no siempre se produce ni en todos los medios: "en todas las informaciones hay parte de valoración, estamos sometidos a presiones sociales, educacionales, etc., y cada uno pone su énfasis en la elaboración de las noticias". Ante el reconocimiento de que "la objetividad no existe", sí apuntan que en medios escritos es más fácil separar información de opinión, más que en medios como la radio y la televisión, donde se encuentran géneros híbridos como las tertulias, los informativos de autor, etc. En este sentido, los encuestados valoran positivamente los informativos de autor como recurso comunicativo, siempre que se distinga que es opinión, "que no se disfrace de informativo normal”. En este punto el ejemplo más citado es el de Iñaki Gabilondo, que "tiene gran credibilidad", aunque también señalan que "es una moda y se ve más el informativo por el presentador que por la información misma". Para otros, "se ha convertido en un periodista de autor con licencia para matar, es un error apostillarlo todo". Por el contrario, muchos señalan el modelo de La 2 de TVE, que ha conseguido hacer un informativo de autor sin opinión. Ante este tipo de formatos la duda que se plantea es si el ciudadano está preparado para analizar y valorar estas opiniones que se vierten con las informaciones.

\subsection{La responsabilidad de los medios de comunicación frente a la ciu- dadanía}

Los medios de comunicación y, en concreto, los periodistas, a la hora de tratar informaciones sobre el honor de las personas involucradas en procesos judiciales, reconocen que se utiliza la "presunción" o el "supuesto" como "fórmula mágica" que en ocasiones vulnera la presunción de inocencia y esto sucede por falta de formación y de conciencia. Aseguran que "se les trata de presuntos delincuentes y no de presuntos inocentes y esto puede durar años por la lentitud de la justicia". En este punto manifiestan que "la formación judicial del periodista es bastante defectuosa y se nota en el día a día". Es más, a veces con ciertas imágenes se hace una clara intromisión en la intimidad, por ejemplo, utilizando imágenes de fuentes policiales que ellos utilizan como parte de la investigación y que no aportan nada a la función informativa de los medios. En este punto reconocen que "nos dejamos arrastrar por la ola sensacionalista de las televisiones". 


\section{Juan Carlos Suárez Villegas, Lorena R. Romero Domínguez,}

\section{Ana Almansa Martínez}

Los límites entre el derecho a la intimidad y a la propia imagen de personajes famosos o de los que desempeñan un cargo público tampoco están claros. El derecho a la intimidad debe estar más ligado al concepto original de intimidad y no tanto al de privacidad. En general, los límites que se reconocen son los puramente legales y, ante la difusión de la legislación, se reconoce que la clave está en la profesionalidad del periodista y el sentido común, excluyendo toda información que no tenga un interés público. Sin embargo, no es necesario ser famoso para que se vulneren la intimidad y la imagen, citándose como ejemplo los testimonios de familiares de personas asesinadas. La difusión de esos momentos trágicos es también una intromisión en la intimidad.

Siendo coherentes con lo anterior, la mayoría no considera periodismo la prensa rosa porque no hacen una buena práctica informativa, se ve más como un espectáculo, un entretenimiento en el cual se vulneran los principios deontológicos de los códigos de la profesión. Aunque se reconoce que para la audiencia puede resultar atractiva al tratar del "factor humano", este tipo de prensa se termina degenerando porque es un mercado que da mucho dinero y, además, consigue devaluar la información "normal", llegando a pedir dinero por hacer declaraciones de cualquier tema. Aunque hay quien opina que "el que no nos gusten los valores que trasmite no quiere decir que no sea periodismo, además su ejercicio, a menudo, es más riguroso que el periodismo serio". Se cita la revista Hola como ejemplo de información seria de crónica social, que no hay que confundir con prensa rosa.

A los colectivos minoritarios se recurre siempre que se puede para "trasmitir y legitimar diversas opciones" porque esto "hace más tolerantes a los receptores." En cuanto a si estos colectivos históricamente desfavorecidos deben ser compensados, se responde que no especialmente, ya que "sería un gravísimo error". Hay que escucharlos, no hacerlos invisibles, pero no hacer compensaciones, así "se habla de ellos cuando es noticia".

En el tema de la violencia contra las mujeres y su tratamiento por los medios de comunicación es unánime la opinión de que se está mejorando mucho, se aplica la "tolerancia cero" y hay códigos éticos, manuales de estilo, colectivos y profesionales que están aportando indicaciones para que el tratamiento mejore. Además, se indica que si no fuera por los medios de comunicación no se estaría haciendo el trabajo judicial ni policial actual, aunque también se reconoce que se está haciendo mal "porque nos hemos criado en un ambiente machista", ante un asesinato se sigue sacando a los vecinos diciendo que "era un chico majo", "parecían una pareja normal", "era alcohólico", algo que no aporta ninguna información sin tener en cuenta que se ha cometido un asesinato. El tratamiento de la violencia se ha convertido en una cuestión de números, "no es necesario contar muertes" "ni el número de puñaladas", incluso se habla de "moda" y no se enfoca el problema social, siendo necesario informar de cada caso sin generalizar para poder llegar a las causas. En general se reconoce que se contribuye a visibilizar la violencia y esto es positivo, aunque hay que seguir unas pautas 
El periodismo en el espejo.

La profesión analizada por periodistas andaluces

informativas claras que eviten el sensacionalismo porque se dedican muchos minutos al morbo.

Los periodistas no estiman que se deba optar por una discriminación positiva de la mujer en el tratamiento informativo. Lo que es noticia es noticia, y hacer de algo noticia para compensar la invisibilidad sufrida por las mujeres puede conducir a una distorsión informativa. No parece sensato "caer en una parcialidad mediática, se debe integrar a todos en la comunicación para intensificar el diálogo social con todo criterio", como declara alguno de los entrevistados. Tampoco en relación con la participación de la mujer en los medios de comunicación consideran que se deba asumir criterios de un trato de favor a las mujeres. Se trata de mantener una igualdad basada en la capacidad y no en el género. En cambio, los partidarios de la conveniencia de la discriminación positiva sostienen que las mujeres no tienen las mismas oportunidades ni condiciones laborales, para aspirar en la profesión ha de demostrar lo que vale y para ello se le pone en la tesitura de asumir roles masculinos. Por otro lado, también se señaló por parte de algunos de los entrevistados la necesidad de visibilizarla como articulistas, como fuentes, como protagonistas, etc., porque forman parte de la sociedad.

Con la presencia de los niños en los programas de televisión son rotundos: esos programas deben desaparecer. Se cuida de ellos en la información, pero en los programas de ocio no se les respeta, "se utilizan sin pudor", aunque la responsabilidad final recae en los padres, al ser ellos los que deciden si los menores deben salir en televisión. En definitiva se reconoce que "los niños son niños y no pueden formar parte de espectáculos ni informaciones" porque "se crean grandes monstruos que quieren ser famosos". La opinión es unánime: "habría que prohibirlos tajantemente, es utilizar la infancia con fines comerciales".

La programación infantil es un tema preocupante, por su escasez, por los valores que transmiten programas no infantiles que se programan en ese horario, por la publicidad que se inserta, dada la ausencia de función formativa y educativa que tienen los medios, que no aplican el Código de Autorregulación en lo que a televisiones se refiere.

En otro orden de cosas, el que los medios de comunicación reproduzcan idearios, proclamas o reivindicaciones de grupos terroristas dependerá del interés informativo que haya sido valorado por el periodista. Se reconoce que silenciarlo no es una solución porque "hay libertad de expresión y la justicia es la que tiene que poner los límites a esta libertad". "Informar es también decir qué pretenden y eso no es reproducir el ideario", es informar en su justa medida para no difundir el terror.

El tratamiento de las imágenes en contextos de tragedias personales, catástrofes o guerras es una "cuestión de sensibilidad". A veces, "la crudeza de las imágenes es útil para poner de manifiesto las barbaridades que la humanidad consiente", "para golpear las conciencias", pero nunca hay que emitirlas fuera de contexto para no caer en el morbo fácil. Se nombra el caso del $11 \mathrm{M}$ y se apunta 
que "era necesario que salieran imágenes para ver la magnitud de la tragedia". Pasado este primer momento, se censuraron para no causar más dolor, poniéndose en el papel de las víctimas y las familias. Por otra parte, se denuncia que se emitan imágenes escabrosas de Irak o de otros conflictos bélicos alejados de España, que deberían ser tratados con la misma sensibilidad que los ocurridos en territorio nacional.

En cuanto a si la libertad de expresión debe quedar condicionada por el respeto a las ideas religiosas hay unanimidad en que nunca debe producirse esta situación. Las ideas religiosas y políticas deben ser respetadas pero no pueden condicionar la libertad de expresión. "La religión forma parte de la intimidad de la persona y no debería importar la opinión sobre el aborto de la Conferencia Episcopal en una sociedad laica".

Los encuestados coinciden en señalar que los medios de comunicación transmiten acertadamente el ideario a los receptores, aunque no está lo suficientemente explicado el entramado económico que sustenta a las empresas informativas y condiciona su línea editorial. Los encuestados coinciden en señalar que el transmitirlo es un derecho y un deber de los medios, es ir "con la verdad por delante". Igual que se conoce la ideología política de los partidos, hay que conocer quiénes están detrás de los medios para conocer mejor la línea editorial y cómo suele haber cambios a lo largo de la vida empresarial.

En cuanto al grado de conocimiento que tienen de la opinión de los ciudadanos (participación a través de la página web, cartas al director, llamadas a la radio y televisión, envío de SMS), la mayoría reconoce que "la comunicación es bidireccional" y que este tipo de información "es importante para el profesional".

\section{CONCLUSIÓN}

Lo que más preocupa a los periodistas andaluces entrevistados es lo que califican como "pésima" situación laboral de los profesionales porque entienden que esta realidad condiciona la información. Aseguran que no sólo la calidad de la información se ve perjudicada por estas circunstancias laborales, sino que también la ética de los periodistas se deteriora. En la misma línea, la inmensa mayoría de profesionales consideran que se está perdiendo el poder crítico del periodismo para convertirse en un escaparate de los intereses económicos y políticos dominantes.

Sin embargo, ningún entrevistado comenta su situación personal o la del medio en el que trabaja. Y es que los entrevistados, en general, no critican ni a sus medios ni a otros profesionales. Escasamente comentan experiencias propias. Más bien se limitan a cuestiones generales. Tampoco entran en cuestiones políticas, ni dejan traslucir su ideología.

Más de la mitad de los entrevistados cree que los medios de comunicación deben de ser controlados por una instancia independiente que vele 
El periodismo en el espejo.

La profesión analizada por periodistas andaluces

por el pluralismo informativo y por la protección de los derechos de los ciudadanos.

Prácticamente la totalidad de los entrevistados sostiene que la autorregulación es fundamental, pero ello no significa que los profesionales consideren que es posible su implantación en la sociedad. La reflexión se plantea sobre si debería darse una corregulación, dado que muchas empresas disponen de un marco para la regulación, aunque no lo cumplan. Para los encuestados, el problema se plantea en los obstáculos que tiene el periodista para autorregularse como consecuencia de la precariedad laboral existente y apuntan como solución "el modelo de quejas norteamericano", donde los problemas de carácter ético se resuelven en la propia redacción.

Para más del $90 \%$ de los encuestados el periodista debe tener una cualificación específica para poder ejercer la profesión, ya que la información es algo demasiado importante como para que la ejerza quien no esté formado. En este sentido, se reconoce el intrusismo como una de las grandes lacras de la profesión y los encuestados se muestran pesimistas a la hora de encontrar soluciones a esta situación.

Por último, debemos destacar que no hay diferencias importantes de las opiniones de los entrevistados ni por sexo ni por edades, salvo en algunas ocasiones puntuales, ya que las respuestas son bastante homogéneas y no hay claras diferencias a la hora de contestar según sea hombre o mujer, más joven o mayor.

\section{APÉNDICE: CUESTIONARIO DE LA ENTREVISTA EN PROFUNDIDAD A LOS PERIODISTAS ANDALUCES}

Ficha técnica del entrevistado/a:

Nombre y apellidos:

Género:

Edad:

Medio:

Posición profesional que desempeña en el medio de comunicación:

Si tiene una licenciatura específica en Periodismo (u otros estudios):

Si está integrado en alguna asociación periodística, sindicato o cualquier forma de organización de la profesión:

\section{Organización profesional y mecanismos de regulación}

1. ¿Considera que los medios de comunicación deben ser controlados por una instancia independiente que vele por el pluralismo informativo y la protección de los derechos del público? 
Juan Carlos Suárez Villegas, Lorena R. Romero Domínguez,

2. ¿Qué opinión te merece la autorregulación de la profesión para establecer límites éticos en el ejercicio del periodismo?

3. ¿Qué organización profesional estimas más conveniente para los periodistas? (sindicatos, colegios, asociaciones, etc.)

4. ¿Crees que debería exigirse una formación específica para ejercer como periodista?

5. ¿Qué medidas concretas crees que pueden tomarse para actuar contra el intrusismo profesional?

6. ¿Consideras que la precariedad laboral afecta al deterioro del ejercicio del periodismo?

7. ¿Cuáles son los derechos de los periodistas que consideras más cuestionados en la práctica profesional? (secreto profesional, cláusula de conciencia, derecho de autor, derecho a un comportamiento ético frente a exigencias contrarias a la deontología profesional, etc.)

8. ¿En qué casos crees que el secreto profesional del periodista podría dejar de ser preservado?

9. ¿Conoces el comité deontológico de la FAPE? ¿Qué opinión te merece?

\section{La independencia del profesional frente a las presiones externas e internas}

1. ¿Cómo crees que debe actuar el profesional ante ciertos regalos o beneficios que puedan ofrecerle empresas, instituciones o particulares que puedan ser objeto de su actividad informativa?

2. ¿Cree que el ejercicio del periodismo informativo resulta incompatible con otras actividades laborales: la publicidad, la política, etc.?

3. ¿Se puede separar la función informativa del medio de comunicación de las presiones que pueda ejercer la empresa para favorecer sus intereses económicos o afinidades políticas?

4. ¿Dónde crees que está el límite entre una noticia que contenga una información pertinente para los intereses del público y la simple intención de utilizarla como promoción comercial?

5. ¿Consideras que el periodismo ha perdido su poder crítico y se ha convertido en escaparate de los intereses económicos y políticos dominantes en la sociedad?

6. ¿Consideras información la actividad realizada por un gabinete de comunicación de una empresa o institución? 


\section{La diligencia en el proceso informativo}

1. ¿Qué piensas de la creciente utilización de cámaras ocultas? ¿Crees que es prioritaria la obtención de cierta información sobre los medios empleados?

2. ¿Publicarías una noticia si no has llegado a contrastarla con las otras partes implicadas?

3. ¿Considerarías suficiente que la noticia te haya sido facilitada por alguna fuente oficial?

4. ¿Admitirías alguna posibilidad de que la fuente pudiera poner condiciones para facilitarte la información?

5. ¿Cuándo considerarías que el off the record puede dejar de ser respetado?

6. ¿Consideras que los medios ofrecen rectificaciones cuando se equivocan y aceptan el ejercicio del derecho de réplica de los afectados a ofrecer su versión de los acontecimientos?

7. ¿Crees que se cuida en la labor informativa la separación entre la información y la opinión?

8. ¿Qué valoración realizarías de los informativos de autor, aquellos en los que su conductor imprime un sello personal a la actualidad a través de sus comentarios y observaciones?

\section{La responsabilidad de los medios de comunicación frente a la ciu- dadanía}

1. ¿Cómo crees que tratan los medios de comunicación el honor de las personas involucradas en procesos judiciales?

3. ¿Cuáles consideras que son los límites del derecho a la intimidad y a la propia imagen de los personajes famosos y de aquellos que desempeñan un cargo público?

4. ¿Consideras "periodismo" la denomina prensa rosa?

5. ¿Cómo consideras que se debe tratar los acontecimientos en los que existe un fuerte dolor familiar por la muerte de un ser querido? ¿Dónde está el límite ante la muerte de una persona?

6. ¿Recurres a la voz de los colectivos minoritarios cuando se ven implicados en alguna noticia?

7. ¿Crees que grupos históricamente desfavorecidos deben ser compensados de alguna manera en los medios?

8. ¿Cómo valoras el tratamiento de la violencia contra las mujeres por parte de los medios de comunicación? 
Juan Carlos Suárez Villegas, Lorena R. Romero Domínguez, Ana Almansa Martínez

9. ¿Crees que se debe hacer una discriminación positiva de la mujer en la comunicación?

10. ¿Qué piensas sobre la utilización de los niños en los programas de televisión?

11. ¿Cómo valorarías la programación televisiva dirigida al público infantil?

12. ¿Cómo valoras que un medio de comunicación reproduzca los idearios, proclamas o reivindicaciones de un grupo terrorista como ETA, Al Qaeda, Hamás o las FARC?

13. ¿Crees que se debería tener especial cuidado en el tratamiento de las imágenes en los contextos de tragedias personales, catástrofes o guerras?

14. ¿Consideras que la libertad de expresión debe quedar condicionada por el respeto a las ideas religiosas?

15. ¿Existe alguna situación, imagen o idea que creas que no se debería publicar por el simple motivo de que sea de mal gusto?

16. ¿Estimas que los ciudadanos tienen derecho a conocer de manera clara la ideología de los medios de comunicación? ¿Cómo crees que deberían explicitarla?

17. ¿Conoces si el medio en el cual trabajas tiene mecanismos establecidos para conocer la opinión de los ciudadanos? ¿Te muestras receptivo a sus sugerencias o críticas?

\section{REFERENCIAS BIBLIOGRÁFICAS}

ALIA, V. (2004): Media Ethics and Social Change. Edinburgh: University Press.

ALMANSA MARTíNEZ, A. (2004): Teoría, estructura y funcionamiento de los gabinetes de comunicación. El caso andaluz. Málaga: Servicio de Publicaciones Universidad de Málaga.

ALSIUS, S. (1998): Ėtica i periodismo. Barcelona: Portic.

ARROYO ALMARAZ, I. (2000): Ética de la imagen. Madrid: Laberinto Comunicación.

AZNAR, H. (2005): Ética de la comunicación y nuevos retos sociales (códigos y recomendaciones para los medios). Barcelona: Paidós.

BELSEY, A.; y CHADWICK, R. (1992): Ethical issues in Journalism and the Media. London: Routledge.

BONETE PERALES, E. (coord.) (1999): Ética de la comunicación audiovisual. Materiales para una "ética mediática". Madrid: Tecnos.

CHRISTIANS, C. (2005): Ethics, Cases and moral reasoning. London: Longman.

CORTINA, A. (dir.) (1997): Rentabilidad de la ética para la empresa. Madrid: Fundación Argentaria-Visor. 
DIEZHANDINO, P.; MARINAS, J.M.; y WAT, N. (2002): Ética de la Comunicación: problemas y recursos. Madrid: Universidad Complutense de Madrid.

FERNÁNDEZ CHRISTLIEB, F. (2002): La responsabilidad de los medios de comunicación. Barcelona: Paidós.

KEEBLE, R. (2003): Ethics for journalists. London: Routledge.

LEPRETTE, J.; y PIGEAT, H. (2004): Ethique et qualité de línformation. París: Presses Universitaires de France.

MARÉCHAL, J.P. (2005): Éthique et économie, une opposition artificielle. París: Presses Universitaires de Rennes.

MCQUAIL, D. (2003): Media accountability and freedom of publication. Oxford: University Press.

PARÉS i MAICAS, M. (1992): Introducción a la comunicación social. Barcelona: ESRPPPU.

PÉREZ FUENTES, J.C. (ed.): Ética periodística (principios, códigos tecnológicos y normas complementarias). Bilbao: Universidad del País Vasco, s/f.

SUAREZ VILLEGAS, J.C. (1999): Medios de Comunicación y Autocontrol: Entre la Ética y el Derecho. Sevilla: Mad.

- (2001): Análisis Ético de la Información: con Casos Prácticos y Documentos Deontológicos. Sevilla: Mad.

- (2001): Principios de Ética Profesional: a Propósito de la Actividad Informativa. Madrid: Tecnos.

- (2006): Los Límites Éticos del Espectáculo Televisivo. Sevilla: Mad.

VIDELA RODRÍGUEZ, J.J. (2004): La ética como fundamento de la actividad periodística. Madrid: Fragua.

\section{Breve semblanza biográfica de los autores}

Juan Carlos Suárez Villegas es Profesor Titular de la Universidad de Sevilla, donde imparte docencia en la Facultad de Comunicación en las materias relacionadas con la ética de los medios de comunicación. Es autor de varias monografías sobre distintos aspectos relacionados con la responsabilidad social de los medios, entre las que podemos destacar: Principios de ética profesional. A propósito de la actividad informativa, La Mujer Construida. Comunicación e identidad femenina, Los límites éticos del espectáculo televisivo.

Lorena R. Romero Domínguez es Doctora en Periodismo y profesora ayudante en la Facultad de Comunicación de la Universidad de Sevilla. Miembro del Grupo de Investigación Estructura, Historia y Contenidos de la Comunicación, de la Asociación de Historiadores de la Comunicación, y tesorera de la Asociación Internacional de Jóvenes Investigadores en Comunicación (AIJIC). 
Juan Carlos Suárez Villegas, Lorena R. Romero Domínguez,

Ana Almansa es profesora en la Facultad de Ciencias de la Comunicación de la Universidad de Málaga, donde imparte las asignaturas Gabinetes de Comunicación, Comunicación Política y Relaciones Públicas Especializadas. Asimismo, es docente en postgrados de las universidades de Almería, Extremadura, Murcia y de la Universidad de Málaga, en la que también coordina el doctorado "Nuevas Tecnologías en Comunicación".

(Recibido el 21-09-2008, aceptado el 06-03-2009) 